\title{
Critiquing workplace learning discourses: \\ Participation and continuity at work
}

\section{Stephen Billett \\ School of Vocational, Technology and Arts Education \\ Griffith University, Nathan 4111, Australia}

Ph: 61-7-3875 5855

Fax: 61-7-3875 6868

Email: s.billett@griffith.edu.au

Billett S (2002) Critiquing workplace learning discourses: Participation and continuity at work Studies in the Education of Adults 34 no 1 pp. 56-67.

\section{Learning, work and participatory practices}

To understand further how learning through work occurs and can be best organised, necessitates setting aside some assumptions embedded in the current workplace learning discourse. It is proposed that workplaces and educational institutions merely represent different instances of social practices in which learning occurs through participation. Learning in both kinds of social practice can be understood through a consideration of their respective participatory practices. Therefore, to distinguish between the two in terms of formalisms of social practice (i.e. that one is formalised and the other informal) and propose some general consequences for learning arising from these bases is not helpful. Both these kinds of social practices are constituted historically, culturally and situationally (Billett 1998), and share a common concern with continuity of practice. The need for workplaces and educational institutions and other kinds of social institutions and practices have evolved over time and are constituted as the product of particular cultural needs (see Scribner 1985). The manifestation of the particular social practice (e.g. a particular workplace or school) is shaped by a complex of cultural needs and situational factors such as local needs, the individuals involved, and the locally-negotiated goals for the activities including bases for judgments about performance (see Engestrom \& Middleton 1996, Suchman 1996). The structuring of learning experiences in workplaces is likely to be directed towards sustaining the practice (Darrah 1996, Pelissier 1991) including sustaining the interests of one or more groups in the practice. Educational institutions also share the goal of continuity. However, there are distinctive qualities in the norms, activities and goals of these two kinds of social practice. Among these differences is the likely claim that educational institutions have learning as their principal and privileged role. However, if learning is seen as something privileged by practices within educational institutions, rather than as a consequence of participation in social practices more generally, (such as those involved in the production of goods or services), this may inhibit understanding about learning generally and learning through work, in particular. However, if, on the other hand, learning is conceptualised more broadly as being the product of participation in social practice (e.g. Rogoff 1995) through individuals’ engagement in its activities and access to its affordances then, it may be possible to adopt a broader view of learning experiences in 
workplaces and their enhancement. The widening acceptance of learning as an inter-psychological process (i.e. between individuals and social sources of knowledge) now prompts a consideration of learning as engagement with the social world, and not only through close personal interactions as Vygotsky (1978) and others propose (e.g. Rogoff 1995).

Other reasons warrant making participation a central concern for a workplace pedagogy. For many workers, perhaps most, the workplace represents the only or most viable location to initially learn and/or develop further their vocational practice. Understanding workplaces as sites for learning has become urgent given the transfer of responsibility for maintaining the currency of vocational practice now being increasingly passed to workers in the current reformulation of lifelong learning policies and practices. In this context, opportunities to engage in work, the kinds of tasks individuals are permitted to participate in, and the guidance provided, become key bases to understand and evaluate how and what individuals learn through their work. How opportunities to participate are distributed in the often contested relations that constitute work practice become central to understanding learning through work. It is important therefore to understand how workplaces afford individuals or cohorts of individuals these opportunities. These affordances also likely shape how individuals elect to engage in goal-directed activities and secure direct (close or proximal) and more indirect (distal) kinds of guidance (e.g. opportunities to observe and listen) (Billett \& Boud 2001). Both kinds of participatory practices have consequences for the knowledge individuals construct, with the former being central to assist with learning that would be difficult without the assistance of a more knowledgeable partner. However, the use of intentional learning strategies in the workplace, such as guided learning, is also subject to contested participatory practices (Billett 2001c).

In order to understand how learning through work proceeds, it is also necessary to account for how individuals elect to engage with work activities and the support and guidance that workplaces afford them, and what they learn. Ultimately, individuals determine what constitutes the invitational qualities of the workplace. Hence, workplace practices such as those shaping individuals' participation and how they elect to engage in workplace activities become central to understanding learning at work and their construction of the knowledge required for work. It is these relations that are central to the social basis of knowing (Scribner 1997/1988, Valsiner \& van de Veer 2000).

It is worth noting that what is proposed here is not intended as a gratuitous critique of educational institutions or practices. Instead, the central concern is to provide a space for learning in the workplace to be discussed at least partially unencumbered from assumptions based on practices in educational institutions.

\section{Workplace participation and sustaining practice}

Describing workplaces as 'informal' learning environments is negative, inaccurate and ill-focused. These descriptions do little to assist the standing of or understanding about workplaces as learning environments. However, the use of negative terms to describe workplaces as learning environments, 
such as 'informal' or 'unstructured', persists. In the following, three distinct premises are advanced to question assumptions that underpin the use of terms to describe learning experiences and outcomes in workplaces.

\section{Negative and inappropriate premises}

Firstly, describing a phenomenon by what it is not: (e.g. informal- 'not formalised', unstructured not structured) is unhelpful. It does little to assist understand its qualities or characteristics. In this instance, the use of concepts and assumptions associated with particular social practices --educational institutions --- are advanced as premises for what constitutes the formalisms and structure of workplace learning experiences. For instance, teaching and learning are commonly, if erroneously, held to be synonymous or at least associated. Therefore, the absence of qualified teachers and didactic interactions in workplaces leads to assumptions that learning will be inferior to that occurring in educational institutions (Collins, Brown \& Newman 1989, Evans 1993, Prawat 1993, Ericsson \& Lehmann 1996). This learning might be seen as ad hoc because the activities are not consistent with practices adopted in these institutions. So, from a perspective that privileges the practices of educational institutions, the absence of a written curriculum document used to plan teachers' actions and learners' experiences (Ericsson \& Lehmann 1996, Marsick \& Watkins 1990, Resnick 1987), and qualified teachers and teaching practices, raises the concern that learning through work may be weak, ad hoc, concrete and incidental. Claims of "ad hockery" are sometimes used to dismiss learning arrangements in places other than formal learning institutions (Prawat 1993, Resnick, 1987). Yet, defining engagement in authentic activities as being unplanned learning activities (Evans 1993), which are incidental (Marsick \& Watkins, 1990), or that intentionality only resides within the learner (Evans 1993) are all imprecise and misleading. Moreover, while there are concerns about the development of conceptual knowledge through experience other than in educational institutions (Evan 1993, Prawat 1993), this concern is also extended to the outcomes of schooling (e.g. Scribner 1984, Raizen 1994). Furthermore, there is evidence aplenty that adaptable learning occurs outside of educational institutions (see below), thereby questioning assumptions about the ad hoc and concrete nature of workplace learning. Consequently, assumptions based on practices in educational institutions may not be wholly useful in considering learning in or the development of a pedagogy for other kinds of social practice, for instance workplaces. Therefore, if the discourse on learning through work uncritically privileges assumptions and practices within educational institutions and learning is not seen as a consequence of engagement in goal-directed activities more generally, then a limited understanding of workplace learning will perpetuate. If, however, the discourse on workplace learning holds learning as an outcome of participant thinking-acting occurring, through engagement in goal-directed activities that are structured by workplace experiences, then this may provide richer bases to discuss and conceptualise workplace learning experiences. 
Structuring of workplace activities, participation and performance

Secondly, it is inaccurate to describe workplace learning experiences as 'unstructured' or 'informal'. Norms, values and practices shape and sustain activities and interactions within workplaces, as in other social practices, such as homes (see Goodnow 1996) or educational institutions. Moreover, the structuring of these experiences in workplaces is often inherently pedagogical as they are directed towards the continuity of the practice through participant learning. Furthermore, workplace norms and practices also structure what constitutes performance in workplaces and bases for judgements about performance. These three points are now discussed in turn.

\section{Constituting workplace experiences}

Rather than being without structure, and without intent, workplace activities are often highly structured, perhaps too structured. Just as the goals, norms and practices of educational institutions frame the activities students participate in, similarly workplace goals and practices determine the tasks and activities that individuals engage in, and which individuals engage in what activities (Billett 1996; Lave 1990; Scribner 1988/1997). Rather than being unintentional, the activities of participants in social practices and their learning are often central to their continuity. Examples include learning to navigate (Hutchins 1983), weaving (Childs \& Greenfield 1980), coal mining (Billett 1993), dairy workers (Scribner 1984), midwifery (Jordan 1989) and tailoring (Lave 1990). Also, rather than being ad hoc, approaches to work practice are often intentionally organised to structure workers' access to the knowledge they need to learn to sustain the practice. Some components of this structuring have been referred to by Lave (1990) as the 'learning curriculum' .

Although not intentionally stated in a syllabus, the pathways of activities in workplaces are often inherently pedagogical, as well as focusing on the continuity of practice through learning. Lave (1990) found that tailors' apprentices learnt by participating in work activities that were sequenced to provide engagement in tasks of increasing accountability and complexity. This pathway of participation incrementally provided greater access to the capacities required for work. The apprentices moved through experiences that first provided access to the overall goals required for performance, then the requirements for performance of particular tasks. For instance, initially, the apprentices finished and ironed completed garments. Engagement in these activities provided opportunities to understand work goals, including the standard of finish demanded for garments, and understanding the shape of garment components. Next, the apprentices learnt specific procedures for constructing garments. The pathway of learning experiences was 'formalised' by a progression through tasks of increasing accountability --- that is, movement from tasks of low to high accountability (i.e. those where mistakes can be tolerated to those where mistakes have significant consequences, e.g. making children's and under garments first). Access to requirements for performance, and indirect guidance through observation were available through the apprentices' participation (Lave 1990). Accordingly, the workplace's norms and practices structured the 
apprentices' activities and shaped their learning. Lave (1993), an anthropologist, concludes that whenever you examine practice you identify learning. The cognitive (e.g. Anderson 1993, Shuell 1990) and sociocultural (e.g. Rogoff 1995) constructivist psychological perspectives also link engagement in goal-directed activities with learning, with the latter emphasising the interpsychological processes that occur through engagement. This engagement is held to reinforce, refine or extend individuals' knowledge. A cognitive account adds that the novelty or routineness of the activities provide opportunities for new learning, and refining and honing what has been learnt from new activities and the support and guidance with new tasks and their refinement (Anderson 1982). Therefore, more than an end in itself, engagement in work activities incites change in individuals' capacities: learning.

Pathways of learning activities have also been identified in contemporary work settings. In hairdressing salons, the tasks apprentices engage in and their progress through these tasks are determined by the particular salon's approach to hairdressing (Billett 2001a). For instance, in one salon where clients are attended to by a number of hairdressers, the apprentices first engage in 'tea and tidy' --- keeping the salon clean and tidy, and providing hot beverages for clients. More than 'busy work', these tasks are necessary components in understanding about and initially participating in hairdressing practice. Through these activities, apprentices learn about hygiene, cleanliness and procedures for determining client needs. This initial participation includes the building of the apprentices' confidence to negotiate with clients. Next, the apprentices wash and then later rinse out of clients' hair the chemicals used to shape and/or colour hair. Engagement in these tasks advances the apprentices' capacities in communicating and negotiating with clients in more intimate ways. The apprentices learn inter-psychologically through direct interpersonal interactions and more indirect kinds of participation (observation and listening) to understand and practice important elements of each task (e.g. the importance of removing all the chemicals), and each task's place and significance in the hairdressing process (Billett 2001a). Later, the apprentices work alongside experienced hairdressers, helping to place rods and curlers in clients' hair. Later still, before being permitted to cut women's hair, they commence cutting men's hair, which is held to be less difficult and of lower accountability than cutting women's hair. The apprentices continue on this pathway of activities until they can style hair independently.

However, in another salon, where each hairdresser undertakes the entire hairdressing task, the apprentice is required to learn to cut and colour far earlier than in the salon referred to above. The structured pathway of activities in the second salon includes gaining competence with procedures that permit early independent practice. Consequently, in the same vocational practice, the particular workplace's goals and practices will determine much of the structuring of activities and also the kinds of tasks to be undertaken and to what standard. The two salons have quite distinct hairdressing goals and practices, and different bases for learning for their continuity. Accordingly, the pathways for participation directed at learning in the two hairdressing practices are structured quite differently, 
thereby reinforcing the localised factors that constitute a particular work practice. Darrah (1996) has also shown how access to work in a computer manufacturing company is organised and sequenced to structure learning through a pathway of activities. In commercial aviation, a pathway exists comprising movement from the role of flight engineer, to first officer through to captain (Hutchins \& Palen 1997).

Other practices have been identified outside of educational institutions associated with learning for continuity of the practice. Hutchins' (1983) study of fishermen identified a deliberately structured approach used in learning to navigate. Substitute objects (shells and other beach debris) were used to represent objects (night star and constellation patterns) that cannot be seen during the day. So where the learning required to sustain the practice (fishing) could not proceed through normal work activities, a substitute activity is provided. The Guarenos of the Orinoco Delta of Venezuela teach cultivation, animal husbandry, hunting and fishing in ways that are highly structured through learning by doing and being provided with an initial understanding of each task and its goals (Ruddle \& Chesterfield 1979, cited in Rogoff \& Gardiner 1984). Jordan, (1989) notes how Yucatan birth attendants learn their profession through the structured observation of more experienced practitioners. Their apprenticeship proceeds with little or no separation between daily working life and the learning of midwifery. These kinds of learning experiences, which are essential to their social practices and communities, would be categorised by many as being 'informal'. However, they are highly structured and formalised by community's norms and practices.

Nevertheless, the structuring of these experiences does not obviate unintended learning occurring. As is proposed below, unintended learning can still occur that is a product of these experiences but does not reflect the kinds of values and practices that were intended to be secured through practice. For instance, Hodges (1998) reports that what she learnt in a teacher education course was quite contrary to what was intended. Moreover, and importantly, the learning arising for these activities is not necessarily concrete --- wedded to circumstances of their construction --- as they can incite adaptable learning. Rogoff (1982) and Rogoff and Gauvain (1984) concluded that the potential for transfer from these kinds of activities was as great as that from schooling. The development of what Vygotsky (1978) refers to as scientific, rather than everyday concepts, is not dependent on whether they were learnt in a school or not, but whether the concepts were made accessible or not (Glassman 2001). So assumptions about the concreteness of learning arising from participation in social practices other than educational institutions need to be critically appraised, particularly in light of the crisis of transfer claimed to be occurring with learning from educational institutions (e.g. Raizen 1994). In sum, although concerned with continuity of practice rather than individual learning, the structuring of workplace activities is often inherently pedagogic. Their pedagogic qualities are shaped by participatory practices: that is how individuals engage in the inter-psychological process of thinking-acting-learning through workplace activities. 


\section{Constituting workplace participation}

Workplaces constitute participatory practices (Engestrom \& Middleton 1996, Suchman 1996). The norms and practices often structure how individuals participate in work. Given the salience of access to the kinds of activities individuals engage in and guidance by more experienced co-workers, how the workplace affords these opportunities is key to the quality of learning through participation. Workplace factors structure and distribute opportunities for participation and, hence, the prospects for learning. Seniority in workplaces (Dore \& Sako 1989) and work demarcations (Danford 1998), as well as internal and external competition, restructuring and redeployment all likely influence the bases of access to work-tasks and guidance, particularly prized opportunities for individual advancement or continuity. Workplace cliques, affiliations, gender, race, language or employment standing and status also influence the distribution of opportunities to participate (Bernhardt 1999, Billett 2001c, Darrah 1996, Hull 1997). Hence, workplace participatory practices are often contested. Indeed, contestation seems an enduring feature of work practice, whether it is between 'newcomers' or 'old-timers' (Lave \& Wenger 1991), full or part-time workers (Hughes \& Bernhardt 1999); teams with different roles and standing in the workplace (Darrah 1996, Hull 1997); between individuals' personal and vocational goals (Darrah 1997) or among institutionalized arrangements such as those representing workers, supervisors or management (Danford 1998). This contestation can determine the distribution of opportunities for engaging in novel activities (from which new learning might be derived) and access to close guidance by more expert co-workers. Those inhibited or excluded from engaging in new tasks and denied access to goals and understandings will likely have more restricted learning outcomes than those invited to participate more fully (Billett 2000). In these ways, the workplace's norms and values shape and distribute opportunities for participation and, therefore, opportunities to learn. That is, they structure the participatory practice of the workplace, and shape how the continuity of practice is directed. However, these values and practices may well be organised to maintain the status and standing of one group of workers (e.g. full-time workers) at the expense of another (e.g. part-time workers). Workplace practices may also reflect employers' attempts to limit the range of tasks and decision-making that workers engage in, in order to maintain the employers' control of the workplace's activities (Danford 1998). Therefore, the bases for maintaining continuity of practice may be complex and contested. Certainly, the tensions between the participatory needs of the individual and the workplace goal of sustaining current norms and practices arise through participation in social practices (Billett \& Boud 2001).

\section{Constituting workplace requirements for performance and its acknowledgment}

What constitutes workplace performance and its acknowledgment is also shaped within workplaces. Situational factors constitute what passes as appropriate performance. The requirement for performance is not a historical (phylogenetic) or socio-cultural given, it is also situationally constituted (Billett 2001b). As judgments about work performance will be made in the circumstances 
of its enactment, there is no such thing as a vocational expert per se. What is taken as expertise in one workplace might be judged inappropriate in another. Moreover, beyond its constitution, how performance is acknowledged and rewarded in the workplace is also determined situationally. In Darrah's (1996) computer manufacturing company, the 'heroes' were those who worked in the systems design area. These workers received accolades and support of a kind that was quite different from what was extended to the production teams, even though their work was as demanding and central to the company's continuity as that of the system designers. In hairdressing salons, it was acceptable for an experienced hairdresser or owner/manager to give a treatment outside the salon's practice, but a novice would be admonished for doing the same.

In sum, the bases for participation and learning in workplaces are constituted by the goals, activities and culture of the work practice (Brown et al. 1989), or what Suchman (1996) refers to as local negotiations and Engestrom and Middleton (1996) refer to as local orderings. This structuring often has inherently pedagogical qualities focused on continuity through participant learning, and extends to constitute how and what is valued as effective workplace practice. Together, the bases advanced above suggest that describing workplace learning as 'informal' or 'unstructured' is far from accurate or helpful.

\section{Learning as a negotiated and reciprocal process}

The third proposition refers to the unqualified use of the term 'informal learning', which limits understanding both learning through work, and learning more generally. To describe the process of learning as being either 'informal' or 'formal' suggests either an irreducible relationship between the circumstances in which the learning occurs and changes in individuals, or that it is possible to approximate that learners engage in a qualitatively different way in different kinds of social practice. That is, that the kinds of circumstances determine the kind of learning that occurs (i.e. those that are 'formal' and those that are 'informal'). Both views promote situational (social) determinism and deemphasise the role of human agency in the construction and further development of their knowledge. Even the most structured learning experiences can only shape individuals' learning. Therefore, it is probably neither helpful nor precise to describe learning outcomes solely on the basis of the structuring of learning experiences. Wertsch (1998) notes how unwelcome social press may lead to a kind of learning, which he refers to as mastery, that is a superficial learnt response to that press. He distinguishes this kind of learning from appropriation where individuals embraces as their own the knowledge to be learnt. Knowledge constructed through mastery is less likely to be exercised voluntarily, as what is appropriated. In considering these relations, Valsiner (1994) refers to the relatedness between the values of the social practice and those of the individual as a basis for the relations between the individual and social practice. So much of the learning that arises may be unintentional - different from what is reflected in the workplace's norms and practices and intended by the workplace. 
So, despite the many contributions to learning arising from participation in social practice, individuals' learning is not socialisation or enculturation. Individual agency also shapes engagement in work practice and what is learnt (Billett \& Boud 2001). Socially constituted personal histories or ontogenies (Cole 1998, Scribner 1985) likely premise this engagement, which result in particular ways of knowing ---- understanding and engaging with the social world. These ontogenies are uniquely socially-shaped through participation in different social practices throughout life histories (Billett 1998). Consequently, individuals' learning will always be unique in some ways, because, as Valsiner (1994) and (Valsiner \& van de Veer (2000) propose, knowledge is co-constructed: reciprocally between the individual and the social experience. Likewise, Meade (1934) also views cognition as an ongoing process of negotiating with the social world in which individuals engage. Therefore, perhaps it is not surprising that individuals dis-identify with the social practice in which they engage (Hodges 1998); workers elect not to engage in team work when it clashes with their cultural more (Darrah, 1997), workers resist training which they believe to be compromising and new recruits ignore and deny affordances intended to assist their participation (Billet 2001a). The tensions here are between continuity as goals for learning: those of the social practice versus those of individuals who participate in those practices.

While acknowledging the contribution of the workplace to shaping the activities individuals engage in and the support they are able to access, it is imprecise to describe the process of learning that occurs as a result of those encounters wholly in terms of the circumstances in which it occurs (i.e. 'informal' or 'formal'). Such descriptions de-emphasise the co-constructive inter-psychological processes between what is afforded by the evolving work practice and how learning is construed ontogenically. This helps clarify the need for terms other than 'informal' or 'formal' in characterising the relations between the circumstances in which individuals engage in activities the consequences for their thinking, acting and learning. Analogously, the relations between workplace participatory practices and individuals' engagement are those that shape learning through work can be thought of being co-participative. These relations are founded, at least in part, on the relatedness of the goals of continuity between the individual and the work practice. Hence, participation and participatory practices may constitute more satisfying conceptual basis to understand this learning.

In sum, it is not helpful to describe or discuss learning in workplaces using discourses and concepts drawn uncritically from practice within educational institutions. Instead, the core of workplace pedagogic practices may be understood through a consideration of reciprocal participatory practice at work, which include the tensions between the goals of individuals continuity as ontogenetic development and the continuity of the work practice including particular interests within the workplace. 


\section{Workplaces as centres of inquiry}

It is worth concluding with a brief consideration of the contributions that inquiries into learning in workplaces can make to understanding further human cognition and development. A focus on practice, participation and engagement in social practice and continuity as ontogeny and changing social practice offers alternative bases for considering both cognition and pedagogy. These alternatives include advancing propositions about learning unencumbered from assumptions about direct relations between teaching and learning. Perhaps the most central concern in contemporary discussions about cognition is to understand the enduring problem of relations between individuals and the social world (Valsiner \& van de Veer 2000). So the conceptual significance of examining participation at work can be seen as illuminating relations between the social world and the mind at intersections between the trajectories of the transforming social practice of the workplace and individuals' ontogenetic development as they engage in work. Rather than proposing the mind as either individual or social, it can be conceptualised as a complex of relations between the two. Here, the relations are seen in terms of participatory practices or engagement founded in intersections between the ontogeny (which is socially derived) and the social practice, and in associations between the continuity or sustaining the two. Workplace practices and affordances, like those in other kinds of social practice (e.g. school, home) are dynamic, as their tasks, goals, interactions, participants and relations are likely to be constantly changing. Moreover, the kinds of inter-psychological encounters that Vygotsky (1978) proposed as leading to intra-psychological outcomes are not the product of single interactions. Rather, they are ongoing and iterative interactions, which likely change in their qualities of interdependence and purpose as, for instance, there is a need to learn novel tasks, or at different stages in individuals' working lives. Rather than being a once-off source of knowing, participation needs to be enduring in order to learn richly as well as remain engaged with the changing requirements for practice.

Procedurally, participatory practices provide useful bases to discuss and appraise learning through work. Their utility arises because of close associations: (i) between engagement in goal-direct activities and learning; (ii) the centrality of access to activities and guidance in inter-psychological processes to access knowledge that has a historical, cultural genesis; and (iii) the need to account for the agency of individuals. As with any learning environment, workplaces' contributions have strengths and weaknesses. Access to activities and guidance through work can render learning opportunities either rich or poor. The participatory factors that make available and distribute these opportunities are not benign, they are distributed on bases that reflect the influence of workplace cliques, affiliations and relationships that are concerned to maintain their standing. The dangers of superficial learning and poor conceptual development are not reserved for educational institutions (e.g. Raizen 1994), as they also beggar the outcomes of learning through work. As with educational institutions, there remains an abiding concern that learning arising from workplace experiences may be fragile and not readily adaptable to new situations and circumstances. All this suggests that a 
workplace pedagogy is needed urgently in order to generate effective (robust) workplace learning. The urgency can be located in the demands of learning throughout working lives being increasingly directed towards individuals who may be ill-placed to secure that development in contested workplaces that may resist their efforts at continuity of practice.

Acknowledgement. I would like to acknowledge the useful and constructive contributions made by the reviewers.

Please note: An earlier version of this paper was presented at Context, Power and perspective: Confronting the Challenges to Improving Attainment in Learning at Work. Joint Network/SKOPE/TLRP International workshop 8-10 ${ }^{\text {th }}$ November 2001, Sunley Management Centre, University College of Northampton

\section{References}

Anderson, J. R. (1993) ‘Problem solving and learning’ American Psychologist, 48 (1) pp.35-44

Anderson, J. R. (1982). 'Acquisition of cognitive skill’ Psychological Review, 89 (4), pp. 369-406.

Berhhardt, A. (1999) The future of low-wage jobs: Case Studies in the retail industry. Institute on Education and the Economy Working paper No 10 March 1999.

Billett, S. (2001a) Learning in the workplace: Strategies for effective practice. Allen and Unwin, Sydney

Billett, S. (2001b) Knowing in practice: Re-conceptualising vocational expertise Learning and Instruction 11 (6) .pp. 431-452

Billett, S. (2001c) Learning throughout working life: Activities and interdependencies. Studies in Continuing Education_vol 23 (1) pp.19-35

Billett, S. \& Boud, D. (2001) Participation in and guided engagement at work: Workplace pedagogic practices. 2nd International Conference on Learning and Work, pp. 321-328, Calgary 26-28 ${ }^{\text {th }}$ July 2001

Billett, S. (2000) 'Guided learning at work’ Journal of Workplace learning. 12 (7) 272-285.

Billett, S. R. (1998) 'Situation, Social systems and learning' Journal of Education and Work. 11 (3) pp. 255-274

Billett, S. (1996) 'Towards a model of workplace learning: the learning curriculum' Studies in Continuing Education. 18 (1) pp. 43-58

Billett, S. (1993) 'What's in a setting --- learning in the workplace' Australian Journal of Adult and Community Education 33 (1) pp. 4-14

Brown J. S. Collins, A. \& Duguid, P. (1989) 'Situated Cognition and the Culture of Learning' Educational Researcher 18 (1) pp. 32-34

Childs, C. P. \& Greenfield, P. M. (1980) 'Informal modes of learning and teaching: the case of Zinacanteco weaving' Advances in cross-cultural psychology Ed. N.Warren vol. 2. Academic Press, London

Cole, M. (1998) 'Can cultural psychology help us think about diversity?' Mind, Culture and Activity, 5 (4) pp. 291-304

Collins, A., Brown J. S., \& Newman, S. E. (1989). Cognitive apprenticeship: teaching the crafts of reading, writing and mathematics. In L.B. Resnick, (ed) Knowledge, learning and instruction, essays in honour of Robert Glaser. (pp. 453-494). Hillsdale, N.J: Erlbaum \& Associates

Danford, A. (1998) 'Teamworking and labour regulation in the autocomponents industry' Work, Employment \& Society 12 (3) pp. 409-431

Darrah, C. N. (1996) Learning and work: An exploration in Industrial Ethnography Garland Publishing, NY

Darrah, C (1997), 'Complicating the concept of skill requirements: Scenes from a workplace', In (G. Hull (ed.), Changing work, Changing workers: Critical perspectives on language, literacy and skills. New York: CUNY Press.

Dore, R. P. \& Sako, M. (1989) How the Japanese learn to work Routledge, London

Engestrom, Y. \& Middleton, D. (1996) Introduction: Studying work as mindful practice. In Y Engestrom \& D. Middleton (Eds.), Cognition and Communication at Work. (pp.1-15). Cambridge: CUP 
Ericsson, K. A., \& Lehmann A. C. (1996) 'Expert and exceptional performance: Evidence of maximal adaptation to task constraints' Annual Review of Psychology, 47, pp. 273-305.

Evans, G. (1993). Institutions: formal or informal learning? Keynote address presented at the International Conference: After Competence: the future of post-compulsory education and Training. Brisbane, 1-3 December, 1993

Glassman, M. (2001) 'Dewey and Vygotsky: Society, Experience, and Inquiry in Educational Practice' Educational Researcher 30 (4) pp. 3-14

Goodnow, J. J. (1996) Collaborative rules: how are people supposed to work with one another. In P B Baltes \& U M Staudinger (eds) Interactive minds: Life span perspectives on the social foundations of cognition. (pp163-197), Cambridge, UK, CUP

Hodges, D. C. (1998) 'Participation as dis-identification with/in a Community of practice' Mind, Culture and Activity, 5 (4), pp. 272-290

Hull, G. (1997) 'Preface and Introduction' Changing work, Changing workers: Critical perspectives on language, literacy and skills ed. G. Hull, State University of New York Press, New York

Hutchins, E. (1983) ‘Understanding Micronesian navigation’ Mental Models Eds D. Genter \& A. Stevens (pp. 191--225) Lawrence Erlbaum, Hillsdale, New Jersey

Hutchins E., \& Palen L. (1997) Constructing meaning from spaces, gesture, and speech. In L. B. Resnick, C. Pontecorvo \& R. Saljo (Eds.), Discourse, Tools and Reasoning: Essays on Situated Cognition. (pp.23-40). Berlin: Springer

Jordan, B. (1989) 'Cosmopolitan obstetrics: Some insights from the training of traditional midwives' Social Science and Medicine vol. 289, pp. 925-44

Lave J. (1993) The practice of learning. In S. Chaiklin \& J. Lave (Eds.), Understanding Practice: Perspectives on Activity and Context_(pp. 3-32). Cambridge: CUP

Lave, J. (1990) The culture of acquisition and the practice of understanding. In J. W. Stigler, R. A. Shweder \& G. Herdt (Eds.), Cultural Psychology (pp. 259-86). Cambridge: CUP

Lave, J. \& Wenger, E. (1991) Situated learning - legitimate peripheral participation_Cambridge; CUP

Marsick, V. J., \& Watkins, K. (1990) Informal and incidental learning in the workplace. London: Routledge

Meade, G. H. (1934) Mind, Self \& Society: Works of George Herbert Meade (volume 1) Chicago. University of Chicago Press

Pelissier, C. (1991) 'The anthropology of teaching and learning’ Annual Review of Anthropology, 20, pp. 75-95

Prawat, R. S. (1993) The value of ideas: Problems versus possibilities in learning. Educational Researcher, 22 (6), pp. 5-16

Raizen, S. (1994) Learning and work: The research base. In Vocational Education and Training for youth: Towards coherent policy and practice. Paris: OECD

Resnick, L. (1987) 'Learning in school and out'. Educational Researcher, 16 (9), pp. 13-20

Rogoff B. (1995) 'Observing sociocultural activities on three planes: participatory appropriation, guided appropriation and apprenticeship', Sociocultural studies of the mind Eds. J.V. Wertsch, P. Del Rio \& A. Alverez (pp. 139-164) Cambridge: CUP

Rogoff, B. (1982) 'Integrating context and cognitive development' Advances in developmental psychology vol. 2 Eds M.E. Lamb \& A.L. Brown (pp. 125--170) Erlbaum, Hillsdale, New Jersey

Rogoff, B. \& Gauvain, M. (1984) 'The cognitive consequences of specific experiences - weaving versus schooling among the Navajo’ Journal of Cross-Cultural Psychology 15 (4) pp. 453-475

Rogoff, B. \& Gardner, W. (1984) Adult Guidance of Cognitive Development, in Rogoff B \& Lave J (eds) Everyday Cognition - its development in social context, Cambridge, Massachusetts: Harvard University Press

Scribner, S. (1997/1988) Mental and manual work: An activity theory orientation. In E. Tobah, R. J. Falmagne, M. B. Parlee, L. M. Martin \& A. S. Kapelman (Eds.), Mind and Social Practice: Selected Writings of Sylvia Scribner. (pp 367-374).Cambridge: CUP

Scribner, S. (1985) Vygostky's use of history. In J. V. Wertsch (ed). Culture, communication and cognition: Vygotskian perspectives_(pp. 119-145). Cambridge: CUP

Scribner, S. (1984) 'Studying working intelligence' Everyday cognition: Its development in social context Eds. Rogoff, B. \& Lave, J. (pp. 9--40). Cambridge, Mass.Harvard University Press

Shuell, T. J. (1990) 'Phases of meaningful learning' Review of Educational Research 26 (4), pp. 531-547 
Suchman, L. (1996) Constituting shared workspaces. In Y. Engestrom \& D. Middleton (Eds.), (1996) Cognition and Communication at Work. (pp.35-60). Cambridge, UK: CUP

Valsiner, J. (1994) 'Bi-directional cultural transmission and constructive sociogenesis' Sociogenesis reexamined Eds W.de Graaf \& R. Maier (pp. 101--134) Springer, New York

Valsiner, J. \& van der Veer, R. (2000) The Social Mind: The construction of an idea. Cambridge CUP

Vygotsky, L. S. (1978). Mind in society - the development of higher psychological processes. Cambridge: Harvard University Press

Wertsch, J.W. (1998) Mind as action New York: Oxford University Press 